\title{
Developing measures for the evaluation of information flow efficiency in supply chains
}

\author{
Authors: \\ Johanna A. Badenhorst-Weiss ${ }^{1}$ \\ Claus Maurer ${ }^{1}$ \\ Tersia Brevis-Landsberg ${ }^{1}$ \\ Affiliations: \\ ${ }^{1}$ Department of Business \\ Management, University of \\ South Africa, South Africa \\ Correspondence to: \\ Hannie Badenhorst-Weiss \\ Email: \\ badenja@unisa.ac.za \\ Postal address: \\ PO Box 392, Unisa, Pretoria \\ 0003, South Africa \\ Dates: \\ Received: 03 Dec. 2012 \\ Accepted: 07 May 2013 \\ Published: 31 May 2013 \\ How to cite this article: \\ Badenhorst-Weiss, J.A., \\ Maurer, C. \& Brevis- \\ Landsberg, T., 2013, \\ 'Developing measures \\ for the evaluation of \\ information flow efficiency \\ in supply chains', Journal of \\ Transport and Supply Chain \\ Management 7(1), Art. \#88, \\ 13 pages.http://dx.doi.org/ \\ 10.4102/jtscm.v7i1.88

\section{Copyright:} \\ (C) 2013. The Authors. \\ Licensee: AOSIS \\ OpenJournals. This work \\ is licensed under the \\ Creative Commons \\ Attribution License.
}

Read online:

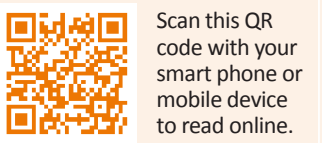

Member organisations in a supply chain are dependent on each other to provide material, services and information to perform optimally in the supply chain. Efficient, unrestricted information flow is needed in supply chains to function properly. Information flow is thus an element of supply chain management that needs to be managed. Yet, no indication could be found in supply chain management literature of the measurement of information flow efficiency. Hence, the aim of this article is to explore the measurement of information flow efficiency in supply chain management (SCM) and exploratively develop possible measures (indicators and associated metrics) to measure the efficiency of information flow.In this research the theory of information and related concepts, the basic notions of information systems and the models of business performance measurement were explored. Based on information flow theory and information flow characteristics a research instrument was developed. It was used in a survey to seek inputs from supply chain managers as to the usefulness of characteristics as indicators and metrics for the measurement of information flow efficiency in a supply chain. The main contribution of the study is the development of a conceptual framework of indicators and metrics that may be used to evaluate the efficiency of information flows in supply chains. The results of this study can be used as a basis for further studies to validate the instrument for measuring information flow efficiency and to develop scales to actually measure information flow efficiency.

\section{Introduction}

The business environment in which organisations operate today is ever changing and becoming more and more complex. Organisations feel increasing pressures that force them to respond quickly to changing conditions and to be innovative in the way they operate. In order for firms to become more flexible and reliable, companies must recondition themselves and adopt new strategies (Turban et al. 2007:3). One of the strategies is the supply chain management (SCM) approach, embraced by organisations across the globe. It was realised that a single firm does not have the technology and resources available to satisfy customer demand and that all companies of a supply chain have a decisive role to play in value adding and in fully understanding and meeting customer requirements. As a result, the member firms of a supply chain began to collaborate and integrate their planning, key business processes and infrastructure across organisational borders (Lambert 2008:1-3). Further progress in information technology enables organisations to share information which has been recognised as one of the most critical factors in building integrated supply chains (Salo \& Karjaluoto 2006; Webster 2008:20).

Supply chain management requires continuous decision-making in five distinct areas: production, inventory, location, transportation and information by each of the supply chain members individually and collectively (Hugos 2006:4-6). The sum of these decisions will define the capabilities and effectiveness of the entire supply chain. Information is mainly required to coordinate daily activities, relating to the functioning and planning of the other four key areas. The information collected at certain points in the supply chain has to flow efficiently between the functions of an organisation and between the member firms of the supply chain (Hugos 2006:16). However, efficient information flow, accuracy, reliability and comprehensiveness are directly associated with effective interoperability between various supply chain partners handling and using this information. Achieving interoperability means faster information flow, and an effective decision-making process (Tyrinopoulos 2004:101).The inability of transferring information correctly, to where and when it is required, will have an impact on the decision making in the four key areas and therefore on the performance of the entire supply chain.

Information sharing in complex linkages, vital to the functioning of the supply chain, would be impossible without efficient information flows. Information sharing is actually required to occur on a real-time basis, to decrease uncertainty between the members of the supply chain and leading to a smoother and more efficient functioning and integration of the supply chain. The flow 
of information in business organisations and particularly in supply chains affects productivity and innovation because it determines the speed by which individuals can act and plan future activities (Wu et al. 2005:1). Therefore it is obvious that information flow needs to be managed in SCM. The measurement of efficient information flow should form an integral part of the management of supply chains. No evidence could be found of the measurement of information flow efficiency in supply chain management literature.

Earlier studies in supply chain management focussed on cost but later performance measures also included customer responsiveness and activity time (Arntzen et al. 1995:69-93; Lee \& Billington 1993:835-847; Pyke \& Cohen 1994:18-94). Beamon (1999) argues that these performance measures are of limited scope and might be inconsistent with the strategic goals of organisations. He developed a framework for the selection of performance measures for supply chain systems. The framework contained three types of measures: flexibility, resource measures and output measures. Sezen (2008:233-240) conducted a study in Turkey and found that there is a positive significant correlation between information sharing and supply chain performance in three categories of performance measures (resource, output and flexibility) in supply chain management. However, no evidence could be found of research done in the measurement of performance or assessment of information flow efficiency.

Other dimensions of information flow were researched. An example is the research done by Li \& Lin (2006:1641-1656). They investigated the impact of environmental uncertainty, intra-organisational facilitators, and inter-organisational relationships on information sharing and information quality in supply chain management. They found that both information sharing and information quality were influenced positively by trust in supply chain partners and shared vision by supply chain partners, but negatively by supplier uncertainty. Furthermore they found that information sharing and information quality are not impacted by customer uncertainty, technology uncertainty, commitment of supply chain partners and IT enablers. These studies contribute to the focus on information flow in the supply chain.

The obvious importance of information flow in the performance of the supply chain necessitates formal management attention. The measurement of the efficiency of information flow should form an integral part of the management of supply chains. As indicated above no evidence could be found of the measurement of information flow efficiency in supply chain management literature. Hence, the aim of this article is to explore the measurement of the efficiency of information flow in SCM and taking the first steps to develop an instrument or framework with measures (indicators and metrics) to measure the efficiency of information flow.

Therefore the main focus points of this article will be information flow, performance measurement and the explorative development of indicators and metrics.

\section{Impact of information and information flow on supply chain performance}

The importance of information flow in a supply chain is obvious in a phenomenon: the 'bullwhip-effect' in many supply chains. Supply chain-wide information sharing between all the entities of a supply chain is necessary (Simchi-Levi, Kaminsky \& Simchi-Levi 2009:154-165). Supply chain information which has been derived only from the supply chain entity immediately ahead (a direct customer) of a supply chain member, may lead to the bullwhip-effect. Busch (2011:2) attributes increasing errors in forecasts to diminishing data quality in those instances where each supply chain partner plans individually without a supply chain-wide data exchange. The bullwhip-effect can be described as the ever-larger ripples in demand forecast errors that travel back through the supply chain caused by slight discrepancies between individual company demand forecasts and real demands or the lack of demand information at each stage of the supply chain. The bullwhip-effect is a direct consequence of a lack of real-time information sharing and efficient information flow through the entire supply chain (Derrick 2003:1; Simchi-Levi et al. 2009:158; Trkman \& Groznik 2006:38).

Ravichandran (2008:77) indicates that the bullwhip-effect has implications on efficiency on various levels. At the macro level, the bullwhip-effect induces poor service levels, inefficiencies in production, scheduling (capacity utilisation), sourcing, distribution, revenue generation and its realisation. At the operational level it generates more (additional) inventory and keeps it in the most inappropriate place to meet a specified service level. At a performance level it can reduce the velocity of cash, destroy potential revenue, and significantly erode revenue realisation through price discounts. It can potentially dilute competitive strategy and position and therefore can be a 'strategy buster'.

The distortion of demand information implies that the manufacturers who only observe their immediate order data will be misled by the amplified demand patterns. This has serious cost implications. For example, manufacturers could incur excess raw materials cost due to unplanned purchases of supplies, additional manufacturing expenses created by excess capacity, inefficient utilisation and overtime, excess warehouse expenses and additional transportation costs due to inefficient scheduling and premium shipping rates (Lee, Padmanabhan \& Whang 2004:1875). In some supply chains the bullwhip-effect can drive $13 \%-25 \%$ of operating costs (Fawcett, Ellram \& Ogden 2007:515). It is clear that a lack of real-time information can have a major impact on supply chain effectiveness and efficiency.

\section{Information, information flow and related concepts}

From a literature review it became clear that the 'flow of information' is closely connected and almost inseparable 
from the concepts 'knowledge transfer' and 'communication'. Logic reasoning will conclude that there is no meaningful flow of information if knowledge is not transferred or if there is no communication. In this section these three concepts will be explored. These concepts have been in use for a long time and recent research and sources do not even define the concepts anymore; 'in ordinary life we seem to be in agreement with the meanings of information and information flow' (Ostalé 2010:1). However, for the purpose of this particular study and article it is necessary to review the traditional descriptions of the concepts again.

Information can be defined in different ways, depending on the context. A general definition of information has been offered by the National Institute of Standards and Technology (National Institute of Standards and Technology [NIST] 2002) by stipulating information to mean 'any communication or representation of knowledge such as facts or data, in any medium or form, including textual, numerical, graphical, cartographic, narrative or audio-visual forms'. Information is also defined as 'an extraction from data that, by modifying the relevant probability distributions, has a capacity to perform useful work on an agent's knowledge base' (Boisot \& Canals 2004:7). Stair and Reynolds (2011:5-7) argue that information is 'a collection of facts organised in such a way that they have additional value beyond the value of facts themselves'. According to these authors information can be extracted from data by applying a transformation process or a set of logical related tasks performed to achieve a defined outcome to the data, which in itself applies knowledge by selecting, organising and manipulating data. Therefore information is data in a transformed usable state.

Reeker and Jones (2002:6-7) furthermore argue that information is transmitted in two different components. Firstly, there exists a physical component, the so-called potential information, capable of transmitting information; however, without attaching any meaning. The second component has been termed mediate information, through which the potential information becomes meaningful. These components are clearly shown in Figure 1.

The flow or exchange of information is often used to model communication (Jonker, Treur \& Wijngaards 2000:1). Specifically relevant to the business environment, Huhtinen and Ojala (2001:6) are of the opinion that the transfer of information between two or more persons or larger entities, such as the departments of a firm or within a firm, is communication.

Figure 1 shows a simple transfer process of information from one person to the next person (Reeker \& Jones, 2002:10), which is an extension of the historical communication model as described by Shannon (1948:379-423, 623-656). The transfer process is shown as an example of potential information being a spoken utterance, transferred by sound waves and the mediate information being some ideas on the relevant mediate information to make the potential information meaningful. The mediate information converting the potential information into meaningful information is partly a set of conventions commonly held by the speaker in the belief that the listener would interpret the information using the same conventions.

For the capture, storage, retrieval and access of current information and knowledge, information technology has widely been used which includes applications that require strong interaction and communication between humans and computer technology.

Grooms (2003:13) and Piltz (2001:1-12) describe human or electronic communication as computer-mediated communication (CMC), which they further define as 'synchronous and asynchronous communication using text messages sent via the computer' and 'the interpersonal communication with the assistance of computers as a transfer medium, transferring spiritual or intellectual content via two spatially separated computers or terminals, connected to a central computer'. The communication between persons, in the case of CMC, is limited to a visual, textual channel, lacking the direct cognitive perception and observation of the communication partner and the situational, physical and social context. Electronic messages, e-mail, electronic discussion forums and computer conferences form part of CMC (Piltz 2001:3). As these forms of communication readily have become part of the communication within the supply chain, they are in use to transfer information which is the focus of this research study.

\section{Drivers influencing information flow efficiency}

Information flow and the control thereof involves many heterogeneous technologies, including but not limited to computers, printers, digital image archiving systems,

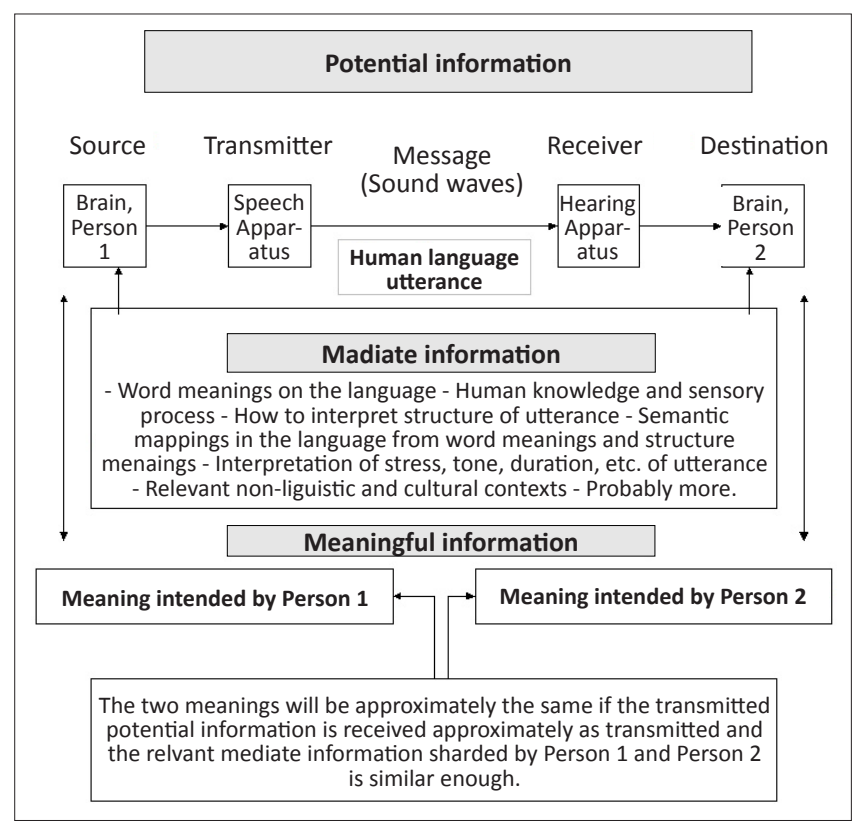

Source: Reeker, L.H. \& Jones, A.T., 2002, 'A new classification of information: A step on the road to interpretability', viewed 30 April 2013, from http://www.isd.mel.nist.gov/research_ engineering/Performance_Metrics/PerMIS_2002_Proceedings/Reeker_Jones.pdf

FIGURE 1: The conveyance of knowledge process. 
electronic records, paper-based records and human speech (Moser 2004:9). Scala Business Solutions NV (2004:7) emphasises that it is vital for a supply chain that crosses multiple companies to generate value that individual participants can see in near real time. This means that systems need to communicate and be able to share information both internally and externally. However, the flow of information or sharing of information can be problematic, and information cannot be assumed to be readily available or to flow uninhibited between two parties (Trkman \& Groznik 2005:562).

Person-to-person information transfer largely depends on the expertise and acquaintance of the persons in the relevant area, social and cultural barriers between the persons and trust, psychological safety and dependence factors between the persons involved (Borgatti 2005:1-2). Saariluoma (2006:1) indicates varying goals of interest and geographic differences as main factors, whilst shared interests of persons exchanging information and personal privacy policies of persons exchanging information form important parameters according to Wu et al. (2005:1).

Newcorn (2003:58) contends that additional variables must be considered in the case of human-to-computer interaction, such as errors in data collection processes, information systems not facilitating inputs, user-friendliness and training in using the system. Access to the computer system (Borgatti 2005:2), information behaviour (Johnstone, Tate \& Bonner 2004:6) and the lack of formal procedures as well as the incompatibility between electronic information systems (Moser 2004:3) have been sited to influence human-tocomputer interaction. Concerning machine-to-machine information transfer, incompatible systems (Moser 2004:3; Newcorn 2003:58), different interpretation of data at different network points or plants (Newcorn 2003:58) and adaptability and limited scalability of proprietary systems (Cisco Systems 2005:4) have to be considered.

From an organisational supply chain perspective, information flow may be differentiated from the viewpoint of organisational levels. On a strategic level, information flow between companies may be inhibited by a lack of trust between the supply chain members (Li \& Lin 2006:1641). This phenomenon specifically occurs, the more independent the member companies are (Trkman \& Groznik 2005:562). Determinants of information flow at operational level within the organisation approximate the decisive factors of information flow between humans and humans, and humans and computers as detailed above.

Despite the level of information flow in the supply chain, or the mode of information transfer, the speed with which information flows from one point to another point in a network of organisations or smaller entities of a supply chain, is also determined by the length of the path between the points or nodes of a network (Borgatti 2005:2). The speed of information flow thus has an influence on business and supply chain efficiency. In many cases companies employ information systems applicable to supply chains in order to improve information flow to its members. The nature of such information systems will be explored in the next paragraph.

\section{Information systems in supply chain management}

Information systems for supply chain management must address the fundamental supply chain process consisting of the activities: buy, make, move, store and sell (operational level in the SCOR model). According to $\mathrm{Oz}$ and Jones (2008:23), each of these activities can be linked to a module in the supply chain management system. Because of the linkage of the activities to different modules and the capability of computing the effects of changes in these activities, information systems allow for the modelling of supply chains. The goal of modelling the supply chain is to capture the interdependency of the different activities that constitute the supply chain and to evaluate the consequences of local decisions on the entire supply chain.

According to Cuenca (2004:242-243) systems that achieve the afore-mentioned tasks have been developed since the realisation of the first computer. Individual material requirement planning (MRP) systems were soon developed into enterprise resource planning (ERP) systems, which are installed throughout the entire organisation and include all the fundamental activities as detailed above. In order to achieve real time updating of the ERP systems, so-called manufacturing execution systems (MES) were utilised. MES typically interface with manufacturing machinery to retrieve the occurrence of events and export the times and dates of such events to the ERP systems. Later developments in supply chain information systems include advanced planning and scheduling systems (APS), which enable companies to improve customer service dramatically and reduce costs (Van Eck 2003:1). Other system improvements emanate from the development of customer relationship and supplier relationship management (CRM \& SRM) modules. Software vendors continuously upgrade and improve their products in an attempt to make the software user-friendlier, and to provide new tools for different industry sectors. Advances in computer technology and the desire for a tighter integrated supply chain in terms of information flows, material and financial flows are driving this development.

According to Swink et al. (2011:530-531) the Internet and other emerging technologies have improved communications, data management, visibility and coordination across global supply chain networks. For example, as sales are made in retail stores, the sales and inventory information is automatically captured by point-of-sale (POS) bar codes and radio frequency identification (RFID) scanners and conveyed through the Internet or other exchanges to a control point. An enterprise resource planning (ERP) or other system then shares this information with suppliers' systems so that inventory records could be updated and replenishment 
orders are generated. Fast moving consumer goods supply chains are usually managed through efficient consumer response through ERP systems (ERP), for example in the grocery industry, and quick response $(\mathrm{QR})$ in the apparel industry.

\section{Business and supply chain performance measurement}

Business enterprises encounter manifold and ever-changing challenges from their business environment and therefore need to constantly monitor and possibly revise their strategies. These strategies include operational, marketing and supply chain strategies.

The decisions that are made with regard to the supply chain should be aligned to the overall corporate strategy of that organisation (Carter et al. 2009:6; Mohamed et al. 2008:153). To assess whether the strategic goals of a business have been achieved, Antić and Sekulić (2006:71) contend that companies use a variety of business performance metrics, which are being assessed periodically. Historically, business performance measurement systems were mainly and often solely financially oriented (Neely 2003:3). However, List and Machaczek (2004:1) as well as Rajamanoharan and Collier (2006:53) argue that financial figures are consequences of yesterday's decisions and do not indicate tomorrow's performance. Therefore businesses need to consider not only financial performance, but also performance in non-financial areas such as customer satisfaction, innovation and internal parameters such as process improvements. For this reason, business performance measurements increasingly include non-financial indicators (Paranjape, Rossiter \& Pantano 2006:5) as used in the balanced scorecard (BSC). The key to business performance management remains the integration of financial, operational and strategic information (Antić \& Sekulić 2006:74; Winkler 2004:1).

According to Coyle, Bardi and Langley (2003:482-485) 'knowing what to measure' influences the overall benefit derived from the measurement process. Business scorecards contain specific indicators and metrics to measure the organisation's performance. A key performance indicator (KPI) may be defined as 'financial or non-financial quantifiable measurements that reflect the critical success factors (key activity) of an organisation' (Von Haaren \& Malyshko 2007:9). According to Giannoccaro, Ludovico and Triantis (2007:91), a performance metric may be defined as quantifying 'the effectiveness and/or efficiency of actions'. 'Measurements are typically expressed in terms of time, quantity, quality or cost' (Hugo, Badenhorst-Weiss \& Van Biljon 2004:100-108). Key performance indicators provide a performance measure for a specific key performance area of an organisation, that is, customer satisfaction, whereas metrics offer performance criteria for activities within a key performance area, such as on-time delivery.

A variation of the business scorecard (BSC) is the corporate communications scorecard (CCSC) which includes communication metrics (Schuppener n.d.). According to this scorecard the added economic gains within the four perspectives of the balanced score-card are measured. Zerfaß (2004:1-7) who proposes the corporate communications score card (CCSC) for the strategic control and measurement of an enterprise, in terms of its communications strategy with its stakeholders, uses the social-political performance of a firm as an additional perspective for measuring communication success. These models are of particular interest to this study as they represent measurement frameworks which already comprise communications metrics.

The performance measurement of either a business or a supply chain is a complex activity (Coyle et al. 2003:482-483). If it is taken into account that a supply chain consists of various organisations, then clearly the measurement of a supply chain is even more complex than that of a single organisation (Hugo et al. 2004:101). There are several key performance indicators (KPIs) for key performance areas (KPAs) which are aimed at judging the performance of logistical and supply chain activities.

There are also a multitude of metrics in use to gauge the performance of supply chains, including, outbound freight cost, order fill rate, finished goods inventory turns, returns and allowances, customer complaints, back orders, order cycle times, forecast accuracy, invoice accuracy to orders processed per time unit, cash-to-cash cycle time and inquiry response. Other metrics used include confirmed fill rate, response delay (in terms of confirming a delivery date), work-in-progress stock (WIP), sales or inventory ratios and sales (Kleijnen \& Smits 2003:1-2).

Santos, Gouveia and Gomes (2006:2-4) propose a supply chain performance measurement framework based on the following four dimensions or perspectives of the BSC:

- customer perspective

- business process perspective

- financial perspective

- innovation and learning perspective.

Each of these BSC perspectives encompasses a number of KPI's, which may be selected depending on the relative level of importance in each business and supply chain. Von Haaren and Malyshko (2007:11) propose a performance measurement framework for supply chain management that comprise five balanced scorecard perspectives, including the four perspectives mentioned above with the additional perspective of 'cooperation'. Both Santos et al. (2006:2-4) and Von Haaren and Malyshko (2007:11) define specific KPIs and the metrics that may be used to evaluate supply chain performance, given certain key assumptions such as strategy and the network selected. According to Santos et al. (2006:2-4) metrics should be linked to business strategy, operational plans, goals of individual departments as well as global goals. It follows therefore that metrics may vary from industry to industry and company to company (Swink et al. 2011:41). 
KPIs and metrics provided by the supply chain scorecard correspond to a large extent with the metrics proposed by the Supply Chain Council's supply chain operations reference (SCOR) model (Simchi-Levi et al. 2009:381; Swink et al. 2011:42). The SCOR model was developed due to a need for finding new ways to communicate objectives and performance outcomes amongst supply chain partners. Besides providing metrics it also provides tools for charting and describing supply chain processes, best practices and technology. The performance measurement or metrics part is of particular use to this study. The SCOR model addresses the following five basic dimensions of performance on the different levels of operation (Swink et al. 2011:42): delivery reliability; responsiveness; flexibility; costs and asset management efficiency.

The measurement process is not merely concerned with the collection of data associated with a predefined standard, with performance measurement rather being perceived as an overall management system, involving the prevention and detection of non-satisfactory performance in a particular key performance area. It is the aim of the measurement process to improve the relevant underlying business process in order to bring about better customer service. In addition, the measurement process is also concerned with the optimisation of the relevant process based on the increased efficiency and effectiveness of the particular process under investigation (Kellen 2003:3-6).

The performance measurement paradigm may be applied in order to develop indicators and associated metrics of information flow efficiency in organisations and/or supply chains.

\section{Sources of indicators and metrics of information flow efficiency}

As it is evident from the literature on the supply chain (Hugo et al. 2004:8; Li \& Lin 2006:1641), the flow of information plays a critical role in the functioning and integration of the supply chain. However, amongst all the metrics which may be applied to assess the performance of the supply chain, there are none to evaluate the efficiency of the information flow throughout the entire supply chain. Accordingly, this article aims to provide a set of possible metrics for the evaluation of information flow efficiency in SCM in order to identify possible areas of improvement in the SCM process.

Real-time contextual data enable users to make better, faster decisions by providing information across both the plant and the supply chain in a single format. The efficiency of information sharing or of the information flow has a direct bearing on the speed with which decisions may be made about the future state of a supply chain. From a performance measurement point of view, the process concerning the information flow efficiency which must be investigated and measured; thus, also involves the methods of information transfer within an organisation and between the member organisations of a supply chain.
Based on the conveyance of the knowledge model, which is based on the traditional communication model (reflected in Figure 1), information that is transferred between two humans is subject to certain conditions. Based on these conditions it is clear that the efficiency of information transfer does not only depend on the speed of the transfer itself, but also on other factors. This interpretation may be derived from the basic definition of efficiency, which is described as 'performing an activity correctly, referring to the economic utilisation of resources' (Mahidhar 2005:58), where the term time refers to the physical time expended whilst the term effort refers to non-time based aspects such as mental and physical exertion. Therefore parameters other than solely time-based indicators and metrics must be considered.

In order to find a source for possible indicators and metrics for the measurement of information flow efficiency, the characteristics applicable to knowledge transfer: software quality and business performance measurement, were consulted as summarised in the previous sections.

A list of characteristics that are applicable to information systems and information quality is reflected below (Lin 2006:8; Stair \& Reynolds 2011:7):

- information accuracy, provides error-free information

- complete information, contains all important facts

- flexible information can be used for a variety of purposes

- reliable information can be depended on

- relevant information is important to decision making

- timely information is delivered when it is needed

- information is verifiable

- information is accessible.

Twenty-six key characteristics of performance measurement system criteria were identified from: Abbadi (2007:1-19); Breyfogle (2008:1-3); De Haas and Kleingeld (1999:233-261); Eckerson (2004:1-5); Jensen and Sage (2000:33-61); Rosella Software (2008:1); Serrat (2010:1-8); Sullivan, McDaniel, Siegel, R\&B Consulting and McDaniel Lambert Inc. (2004:2-4); Ying, Hong and Zhengchuan (2004:4-6). Upon closer examination of the 26 characteristics a narrowed down 'duplicate-free' list of characteristics were retained. These characteristics are reflected in Box 1.

The characteristics below may serve as indicators to assess performance if each characteristic is associated with particular activities. For example, it is not possible either to observe or to measure timeliness as an efficiency measurement. Timeliness must be linked to an activity (metric), for example, the time required to respond to the receipt of an order, or the time

BOX 1: Master list of characteristics of performance measurement systems.

\begin{tabular}{|ll|}
\hline - Relevance & - Repeatability \\
- Responsiveness & - Interpretability \\
- Acceptability & - Comprehensiveness \\
- Usefulness & - Believability \\
- Consistency & - Accessibility \\
- Security & - Timeliness \\
- Accuracy & - \\
\hline
\end{tabular}


required to process incoming emails. In both these cases the timestamps on either a faxed document or on the electronic document may be examined to yield a measurement of the delay between the incoming and the outgoing message. The following section discusses the extraction of suitable indicators and associated metrics from the characteristics identified.

\section{Developing indicators and associated metrics for information flow efficiency in supply chain management}

In an attempt to develop indicators and associated metrics for information flow efficiency in supply chain management, the measurement framework similar to the BSC, the SCOR model and the supply chain scorecard - an example shown in Table 1 below- was followed. Characteristics of measurements applied in different fields of information transfer, business performance measurement and information technology (identified above) formed the basis of the empirical study to determine the usefulness of these characteristics to serve as a basis to develop indicators and measures to measure information flow efficiency in the supply chain.

In the example in Table 1 the objective is information flow efficiency, and it will be measured by an appropriate indicator such as information integration percent and possible metrics will be transmission time and information cycle time. For each information flow indicator (derived from the list of characteristics of information flow shown in Box 1) appropriate metrics were developed that was included in the research instrument (questionnaire) for the empirical study. A summary of the description of the characteristics to be converted in indicators and metrics is provided below.

\section{Accessibility}

In statistical terms accessibility is used to describe the ease and the conditions under which statistical information may be obtained (Organization of Economic Co-operation and Development [OECD] 2006a). In terms of information flow, accessibility takes into account the ease of obtaining information and the user-friendliness of interfaces aiding the access of data or information. Possible measurable questions to be asked in assessing this measure include:

- Are there obstacles to overcome in accessing information?

- Are the access screens for information retrieval user-friendly?

- Is information access personalised?

- Is the user able to choose his or her own information content?

- What is the relative cost of accessing information or data?

TABLE 1: Information flow efficiency measurement framework.

\begin{tabular}{ll}
\hline Measurement framework & Example \\
\hline Objective & Information flow efficiency \\
Indicator & Information integration persent \\
Metric & Average Information transmission time (seconds) \\
& Information cycle time (hours) \\
\hline
\end{tabular}

\section{Interpretability}

Interpretability relates to the verb, 'to interpret', which means to bring out a meaning of something or 'to explain' (Dictionary.com 2008b). Interpretability relates to the concept of 'understandability'. With regard to information flow interpretability could be linked both to the ability to read the content of the data or information, as well as to the ambiguity of the content retrieved from the data or information by different persons. A set of possible measurable questions include:

- Are the variables in the presentation of the information or data clearly defined?

- Is the classification or division of the information or data understandable?

- Are help functions available to explain how the information or data is derived?

- Is multilingualism taken into account?

\section{Consistency}

Consistency refers to the steadfast adherence to the same principles, course, form, in agreement, harmony, compatibility, correspondence or uniformity amongst the parts of a complex phenomenon (Dictionary.com 2008a). For example, concerning financial information, 'consistency' implies conformity from period to period without any changes in policies and procedures. In the sense of information flow consistency the uniformity and stability of the data or information which is being either transferred or retrieved are important. The main issue is; thus, whether uniform and correct data or information is possible, even if it is retrieved from or transferred to different sources. Possible measurable questions to be used in assessments include:

- Is it possible to compare information or data of the same nature between different sources?

- Are changes to the presentation of information or data communicated globally?

- Is the process of information or data provision or derivation clearly defined?

\section{Timeliness}

Timeliness refers to the speed with which the dissemination of data takes place, that is, the lapse of time between the end of a reference period (or a reference date) and the dissemination of the relevant data (Organization of Economic Co-operation and Development [OECD] 2006b). Information is timely when it is available to the decision maker before it loses its ability to influence the relevant decision. Timeliness, in the sense of information flow, is related to the time it takes to provide the information and whether it is possible to produce the information on time. However, of equal importance is the response time to certain information received. This may be considered as one of the most important factors influencing information flow efficiency. The following possible measurable questions were identified:

- How long does it take to retrieve information or data?

- Is the information or data always produced on time? 
- What is the time difference between the receipt and reading of e-mails or faxes?

- What is the time difference between the receipt and responding to e-mails or faxes?

- Is late or missing information or data communicated?

\section{Relevance}

Relevance is a term used to describe how significant, connected, or applicable something is to a given matter at hand (Merriam-Webster 2010a). 'Relevance' refers to the capability of the information to make a difference to a specific decision. In terms of information flow, relevance may be construed as involving the applicability of the information presented to the actual situation under review, whilst the information is also capable of making a difference to a specific decision. Accordingly, possible questions to follow:

- Does the information or data presentation meet the needs (too much or too little)?

- Can the information or data presentation and content be adjusted to future needs?

- Is the information or data regularly reviewed (are feedback programmes in place)?

- Are the information or data priorities considered?

\section{Accuracy}

Accuracy refers to the degree of conformity of a measure to a standard or true value (Merriam-Webster 2010b). This characteristic of 'accuracy' relates closely to the definition of verifiable information which is information which is considered to be free from error. Accuracy with regard to information flow deals with the correctness of the data or information which is used to make decisions. Possible measurable questions include:

- Is the information or data always correct?

- What is the number of corrections required to amend the information or data produced?

- Does a quality standard for information or data collection or presentation exist?

- How is both internal and external data accuracy checked?

- How is faulty or erroneous data treated?

- Are accuracy levels for the information or data specified?

\section{Security}

Security in terms of information systems is defined as the protection of information systems against both the unauthorised access or modification of information or data, whether in storage, being processed or in transit as well as the denial of service to authorised users or the provision of service to unauthorised users. Security therefore includes those measures necessary to detect, document, and counter such threats (University of Nevada 2010). Possible measurable questions include the following:

- Is detailed information or data protected against unauthorised access?

- Is detailed information or data protected against unauthorised change?

- Is detailed information or data backed up regularly?

\section{Acceptability}

Acceptability refers to being capable or worthy and generally approved (Merriam-Webster 2009d). Acceptability with regard to information flow is concerned with the acceptance of the general format and the personalisation of the layout of the information or data. Possible measurable questions include:

- Do all the users of the information or data agree with the presentation or layout of content?

- Is it possible to customise or personalise the information or data layout easily?

- Do specific users of the information or data use the information or data presentation?

\section{Usefulness}

Usefulness refers to the quality of having utility and, especially, practical worth or applicability (MerriamWebster 2009a). Usefulness refers to the overall, qualitative characteristics of the quality of the information or data. Usefulness in information flow may be interpreted as how well used the particular information is, in terms of the frequency with, and the level at which the information or data presented is consulted when ascertaining the status of a particular project or situation. The following possible measurable questions were formulated:

- Is all the information or data contained in the presentation useful to the user?

- Does the use of specific information or data dissipate over time?

- Is the information or data produced useful to all the users, from the strategic to the operational level?

\section{Believability}

Believability may be defined as the capability of being believed, with believed being accepted as true (MerriamWebster 2009b). In relation to information flow, believability clearly concerns the correctness of the information or data contained in a report or query, as well as the continued correctness of the specific information or data. Incorrect information may occur as a result of either incorrect query design or multiple versions of this information or data being kept at different locations without consistent version control. This relates closely to the financial definition of verifiable information which is considered to be information which is free from error. It also implies that the information is reliable. Reliability assures decision makers that they may depend on the information to be effective in terms of doing what it is expected to do. The following possible questions are relevant:

- Is the information or data perceived to be always correct?

- How often has incorrect information or data surfaced in reports or presentations?

- Do multiple versions of information or data exist on personal computers, networks and in the paper archives?

- Are older versions of the information or data mixed with newer versions? 


\section{Repeatability}

Based on a statistical concept, repeatability is the concept of survey procedures being repeatable from survey to survey and from location to location. In other words, the same information or data, processed twice, should yield the same results (Organization of Economic Co-operation and Development [OECD] 2002). Repeatability may be linked to the concept of comparability, which refers to the quality of information that enable users to identify similarities in, and differences between, two sets of economic phenomena. With regard to information flow efficiency, repeatability deals with the fact that it is possible to obtain the information or data for a second time by providing the same input parameters. However, repeatability may be inhibited when long time periods are required to produce the information or data, whilst the actual information or data may change far more quickly. This may be the case in real-time transaction systems, where data input may change unannounced and, thus, influence the results of a report or query. Although this phenomenon may be desirable in certain performance areas of the organisation this would; however, have to be clearly stipulated. Based on this reasoning, the following possible measurable questions were identified:

- Is it possible to reproduce this information or data within days?

- For which period is the information or data valid compared to the time required to produce it?

- Would it be possible to repeat the information or data if it was reproduced from different report tools?

\section{Responsiveness}

Responsiveness may be defined as quick to respond or to react appropriately (Merriam-Webster 2009c). Responsiveness in terms of information flow deals with the time delay between the actual information or data becoming available and the actual possibility of being able to retrieve it from, for example, an enterprise resource planning system. The following measurable questions could possibly be asked:

- What is the time difference between the occurrence of activities and reporting of those activities?

- Are reports or information updated as soon as the information or data changes?

- Is transactional data updated real-time?

\section{Comprehensiveness}

Comprehensiveness involves covering a topic completely or broadly (Merriam-Webster2009e). Information flow comprehensiveness covers the overall completeness of the information or data required in order to arrive at meaningful decisions based on the information or data. The following possible measurable questions were identified:

- Does the information or data produced cover all required aspects or variables?

- Do reports or information cover all requirements at all organisational levels?

- Is the information or data cascaded upwards into the next level indicators?

1.Repeatability is also called reproducibility (Organization of Economic Co-operation and Development [OECD] 2002a), Glossary of statistical terms.

\section{Research strategy}

In this study the aim was to develop possible indicators and associated metrics for information flow efficiency in supply chain management by identifying the characteristics relevant to the fields of business performance measurement, information, information flow and software quality (literature study) and to seek input from managers (respondents) in supply chains about the usefulness of these characteristics (converted into questions) to possibly measure information flow efficiency (empirical study).

\section{Research Approach}

The research strategy for this explorative study was a combination of a literature study, an empirical survey in supply chains using a quantitative measuring instrument in the form of a questionnaire, as well as the necessary methods of statistical analyses.

\section{Measuring Instruments}

To develop an instrument for measuring the information flow efficiency in supply chains, characteristics of information quality and performance measurement systems were used and converted into a questionnaire. The questionnaire was used in a survey in a supply chain to determine the most useful measures: indicators and metrics for information flow efficiency. The respondents were asked to rank and rate the importance of these characteristics as possible evaluation criteria (indicators and metrics) for determining information flow efficiency in supply chains.

\section{Participants or respondents}

Initially the researcher used a random sample of 348 firms belonging to the steel and plastics industry in South Africa. However, only two responses were received. The researcher contacted all the members in the sample to seek their cooperation but no additional response was obtained. The researcher was then forced to apply purposive sampling by approaching senior and executive managers in the supply chain where the researcher was employed in a telecommunications cable manufacturing supply chain. The sample comprised of 32 suppliers of materials and services in the telecommunications cable manufacturing supply chain. Through personal contacts the researcher could persuade the respondents to participate in the study. The survey was conducted by means of personal interviews.

\section{Statistical Analysis or Treatment of data}

The survey questionnaires were analysed using statistical methods with the aid of the MYSTAT program. It was not possible to use standard inferential statistical procedures involving the mean and standard deviation due to the small sample, sampling method and data type (ordinal). Instead it was necessary to apply nonparametric statistics. In order to evaluate the distribution of the characteristics or indicators of information flow efficiency, a box plot diagram was used to 
evaluate the spread of the data. When computing a measure of location for this data, the medians were used rather than the means.

The selection of the indicators of information flow efficiency was explored by utilising statistical hierarchical clustering procedures. The assessed importance of the indicators was statistically evaluated by applying a cluster analysis, which seeks to identify homogenous subgroups of cases or variables. Ward's method was used to evaluate distances between variables in a multidimensional space and to agglomerate variables into clusters (Dolnicar 2003:5-12).The results of the cluster analysis and the median importance ranking determined the selection of the master set of indicators.

\section{Findings}

The results of the ranking of the indicators of information flow efficiency from the most important to the least important are shown in the first column in Table 2. Each indicator had to be ranked on a scale form ' 01 ' to ' 13 '. The most important indicator will be a '01', the second most important a '02',

TABLE 2: Median Importance rankings and ratings indicators and associated metrics.

\begin{tabular}{|c|c|c|c|}
\hline Indicator & Median Ranking & Metric & Median of Importance \\
\hline \multirow[t]{5}{*}{ Accessibility } & 6.0 & Access to information & 1.0 \\
\hline & & User-friendly access screens & 2.0 \\
\hline & & Personalised access & 3.0 \\
\hline & & Choice of own information content & 3.0 \\
\hline & & Relative cost of accessing information & 3.0 \\
\hline \multirow[t]{4}{*}{ Interpretability } & 9.0 & Clearly defined variables in information representation & 1.0 \\
\hline & & Understandable classification & 2.0 \\
\hline & & Availability of help functions & 2.5 \\
\hline & & Consideration of multilingualism & 4.0 \\
\hline \multirow[t]{3}{*}{ Consistency } & 6.5 & Comparability & 2.0 \\
\hline & & Enterprise-wide communication of changes & 2.0 \\
\hline & & Clearly defined process of information provision & 2.0 \\
\hline \multirow[t]{4}{*}{ Timeliness } & 7.0 & Time taken to retrieve data & 2.0 \\
\hline & & On-time provision of data & 1.5 \\
\hline & & Time difference between receipt and responding & 2.0 \\
\hline & & Reporting of late or missing data & 2.0 \\
\hline \multirow[t]{4}{*}{ Relevance } & 5.0 & Meeting needs of data presentation & 2.0 \\
\hline & & Ability of content to adjust for future needs & 2.0 \\
\hline & & Regular review of information needs & 3.0 \\
\hline & & Consideration of information priorities & 2.5 \\
\hline \multirow[t]{6}{*}{ Accuracy } & 2.5 & Correctness & 1.0 \\
\hline & & Number of corrections required & 2.5 \\
\hline & & Existence of quality standards for information & 3.0 \\
\hline & & Control of information consistency & 2.0 \\
\hline & & Treatment of erroneous data & 2.0 \\
\hline & & Specified accuracy levels for information & 2.0 \\
\hline \multirow[t]{2}{*}{ Security } & 5.5 & Protection from unauthorised access & 1.0 \\
\hline & & Protection from unauthorised change & 1.0 \\
\hline \multirow{2}{*}{ Acceptability } & & Easily customised information layout & 2.0 \\
\hline & & The use of specific layout to specific users & 3.0 \\
\hline \multirow[t]{3}{*}{ Usefulness } & 4.5 & Usefulness to user & 2.0 \\
\hline & & Fading of use of data presentation over time & 3 \\
\hline & & Usefulness of data to all users from strategic to operational level & 2.0 \\
\hline \multirow[t]{4}{*}{ Believability } & 7.0 & Correctness of data & 1.0 \\
\hline & & Number of wrong data incidences & 2.0 \\
\hline & & Existence of multiple versions of data & 3.0 \\
\hline & & Interchanged older data with newer versions & 2.0 \\
\hline \multirow[t]{3}{*}{ Repeatability } & 9.0 & Repeatability of data if reproduced multiple times within days & 2.0 \\
\hline & & Period of validity of data & 2.0 \\
\hline & & Repeatability if reproduced form different report tools & 2.0 \\
\hline \multirow[t]{3}{*}{ Responsiveness } & 7.0 & Time delay between occurrence and report of transaction & 2.0 \\
\hline & & Real-time updating of reports & 1.0 \\
\hline & & Real-time updating of transaction data & 2.0 \\
\hline \multirow[t]{3}{*}{ Comprehensiveness } & 11.0 & Data covering all aspects required & 2.0 \\
\hline & & Reports/information covering requirements of all organisational levels & 2.0 \\
\hline & & Ability to cascade into next level performance indicator & 2.0 \\
\hline
\end{tabular}


the third most important a '03' until the least important indicator is marked with a '13'. The results showed that 'Accuracy' was ranked most important, with a median of 2.5, followed by 'Usefulness', 'Relevance', 'Security', 'Accessibility' and 'Consistency' with medians of 4.5; 5.0; 5.5; 6.0 and 6.5. 'Believability', 'Timeliness' and 'Responsiveness' were ranked with a median of 7.0, 'Repeatability' and 'Interpretability' were ranked with medians of 9.0, whilst 'Acceptability' and 'Comprehensiveness' received median rankings of 11, denoting least importance.

Table 2, columns two and three, depicts the evaluation results of the medians of importance of the metrics relating to each of the indicators as detailed above.

The metrics were each rated on a scale from ' 01 ' to ' 05 ', with ' 01 ' being the most important and '05' the least important. Based on the results above, a bias towards more important ratings could be detected, as none of the metrics were judged as least important and only one metric, 'multilinguism', as having little importance.

The associations computed by the clustering algorithm also depend on the number of clusters chosen in order to achieve a sensible cluster schedule. By using the cluster analysis technique together with the box plot diagram, the appropriate cluster membership schedule was identified. The important characteristics could be segregated from the less important ones in order to limit the amount of data to be handled and to focus on what was thought to be important by the respondents. After eliminating the least important ones the remaining characteristics where used as indicators of information flow efficiency. The indicators retained were: 'Accessibility', 'Consistency', 'Timeliness', 'Relevance', 'Accuracy' and 'Usefulness', including their associated metrics.

\section{Conclusion}

Information sharing in complex linkages, vital to the functioning of the supply chain, would be impossible without efficient information flows. Information sharing is actually required to occur on a real-time basis, to decrease uncertainty between the members of the supply chain and leading to a smoother and more efficient functioning and integration of the supply chain. The flow of information in business organisations, and particularly in supply chains, affects productivity and innovation because it determines the speed by which individuals can act and plan future activities. The information flow therefore needs to be managed in supply chains. No evidence could be found of the measurement of information flow efficiency in supply chain management literature. Hence, the aim of this study: to explore the measurement of information flow efficiency in SCM and to develop possible measures (indicators and metrics) for measuring the efficiency of information flow. In this research the concepts of supply chains, supply chain management, the theory of information and related concepts, the basic notions of information systems and the models of business performance measurement were explored. By the application and combination of these theories, it was possible to develop possible indicators and associated metrics for the determination of information flow efficiency in supply chains.

Because of the small sample size and the fact that a purposive sample was used, the results of this research are exploratory in nature and further research is required to validate the set of proposed indicators and metrics. Scales need to be developed for each metric to actually measure performance. The shortcomings of this study pose opportunities for further research.

In conclusion, the development of indicators and metrics from characteristics of related concepts and existing performance evaluation instruments in this study, makes a contribution to supply chain management's understanding of the enterprises' and supply chains' performance attributable to information flow efficiency.

\section{Acknowledgements Competing interests}

The authors declare that they have no financial or personal relationship(s) that may have inappropriately influenced them in writing this article.

\section{References}

Abbadi, Z., 2007, 'Security metrics: What can we measure', Open Web Application Security Project (OWASP), Nova Chapter meeting presentation on security metrics, viewed 02 July 2011, from http://www.owasp.org/index.php/ File:Security_metrics-_what_can_we_measure-Zed_Abbadi.pdf

Antić, L. \& Sekulić, V., 2006, 'New paradigm of business performance measurement in contemporary business conditions', Facta Universitas Series: Economics and Organization 3(1), 69-77.

Arntzen, B.C., Brown, G.G., Harrison, T.P. \& Trafton, L.L., 1995, ‘Global supply chain management at a Digital Equipment Corporation', Interfaces 25(1), 69-93. http:// dx.doi.org/10.1287/inte.25.1.69

Beamon, B.M., 1999, 'Measuring supply chain performance', International Journal of Operations and Production Management 19(3), 215-219. http://dx.doi. org/10.1108/01443579910249714

Borgatti, S., 2005, 'Facilitating Knowledge flows', Carroll School of Management, Boston College, USA, viewed 31 July 2006, from http://www.socialnetworkanalysis.com/ knowledge_sharing.htm

Boisot, M. \& Canals, A., 2004, 'Data, information and knowledge: have we got it right?', Universitat Oberta de Catalunya, Barcelona, Catalonia, Spain, viewed 17 June 2011, from http://www.uoc.edu/in3/dt/20388/index.html

Breyfogle, F.W., 2008, 'Good metrics for balanced scorecard performance', Modified excerpt from the book, The integrated enterprise excellence system: An enhanced, unified approach to balanced scorecards, strategic planning and business improvement, viewed 06 September 2010 from http://www.smartersolutions. $\mathrm{com} / \mathrm{blog} /$ forrestbreyfogle/? $\mathrm{p}=148$

Busch, A., 2011, ,Collaborative supply chain management (CSCM), Fraunhofer ALB analysiert und vergleicht 19 Systeme zur synchronisierten Planung und Steuerung der Supply Chain', viewed 25 May 2011, from http://www.competence-site. de/pps-systeme/Collaborative-Supply-Chain-Management-CSCM-FraunhoferALB-analysiert-vergleicht-19-Systeme-zur-synchronisierten-Planung-SteuerungSupply-Chain

Carter, P.L., Monczka, R.M., Ragatz, G.L. \& Jennings, P.L., 2009, 'Supply chain integration: Challenges and good practices', CAPS Research, Institute for Supply Chain Management and WP Carey School of Business at Arizona State University.

Cisco Systems, 2005, 'IP-based network support defence transformation', A Cisco Intelligent White Paper, Cisco Systems Inc., California, USA. 
Coyle, J.J., Bardi, E.J. \& Langley, C.J., 2003, The management of business logistics: A supply chain perspective, 7th edn., Canada, South-Western/Thomson Learning.

Cuenca, J.M.M., 2004, 'El futurotecnologico de lasterminalesmaritimas de vehiculos: La integracion de sus sistemas de informacion', Doctoral thesis, Dept. de Ciencia I EnginyeriaNautiques, Universitat Politecnica de Catalunya.

De Haas, M. \&Kleingeld, A.D., 1999, 'Multilevel design of performance measurement systems: Enhancing strategic dialog throughout the organization', Management Accounting Research 10, 233-261. http://dx.doi.org/10.1006/mare.1998.0098

Derrick, R.D., 2003,'Challenging the bullwhip effect with advanced information sharing', Accenture Outlook Point of View, USA, March 2003.

Dictionary.com, 2008a, Consistency, viewed 11 January 2009, from http://dictionary. reference.com/browse/consistency

Dictionary.com, 2008b, Interpretability, viewed 11 January 2009, from http:// dictionary.reference.com/browse/interpretability

Dolnicar, S., 2003, 'Using cluster analysis for market segmentation: Typical misconceptions, established methodological weaknesses and some recommendations for improvement', Journal of Market Research 11(2), 5-12.

Eckerson, W., 2004, 'Best practices in business performance management: business strategies', excerpt from the full report, The Data Warehousing Institute (TDWI), Europe.

Fawcett, S.E., Ellram, L.M. \& Ogden A, 2007, Supply chain management: from vision to implementation, Upper Saddle River, NJ, Pearson Prentice-Hall.

Giannoccaro, R., Ludovico, A.D. \& Triantis, K., 2007, 'A structured methodology for developing performance measures in any environment', Advances in Production Engineering \& Management 2(2), 91-99.

Grooms, L.D., 2003, 'Computer-mediated communication: A vehicle for learning', Regent University School of Education, viewed 13 June 2005, from http://www. irrodl.org/content/v4.2/grooms.html

Hugo, W.M.J., Badenhorst-Weiss, J.A. \& Van Biljon, E.H.B., 2004, Supply chain management: Logistics in perspective, 1st edn., Pretoria, South Africa, Van Schaik. PMCid:1388732

Hugos, M., 2006., Essentials of supply chain management, New Jersey,Wiley.

Huhtinen, H. \& Ojala, T., 2001, 'Case study from the finish ICT industry: Communication aspects and the use of communication tools', Lappeenranta University of Technology, Finland.

Jensen, A.J. \& Sage, P.B., 2000, 'A systems management approach for improvement of organization performance measurement systems', Information, Knowledge, Systems Management 2(2000), 33-61.

Johnstone, D., Tate, M. \& Bonner, M., 2004, 'Bringing human information behaviour into information systems research: an application of systems modelling' into information systems research: an application of systems modelling',
Information Research (9)4, July, Paper 191, viewed 15 May 2011, from http:// Information Research (9)4, July, Paper

Jonker, C.M., Treur, J. \& Wijngaards, W.C.A., 2000, 'An executable model between verbal and non-verbal communication', Department of Artificial Intelligence,Vrije verbal and non-verbal communication', Department of Artifici
Universiteit Amsterdam, The Netherlands. PMCid:2363220

Kellen, V., 2003, 'Business Performance Measurement', viewed 16 May 2005, from http://www.performance-measurement.net/news-detail.asp?nID =55

Kleijnen, J.P.C. \& Smits, M.T., 2003, 'Performance metrics in supply chain management', Journal of the Operational Research Society 54(5), 507-514. http:// dx.doi.org/10.1057/palgrave.jors.2601539

Lambert, D.M., 2008, Supply chain management: Processes, partnerships, performance, 3rd edn., Florida, Supply Chain Management Institute.

Lee, H.L. \& Billington, C., 1993, 'Material Management in decentralised supply chains', Operational Research 41(5), 835-847. http://dx.doi.org/10.1287/opre.41.5.835

Lee, H.L., Padmanabhan, V. \& Whang, S., 2004, 'Information distortion in a supply chain: The bullwhip effect', Management Science 50(12), 1875-1886. http:// dx.doi.org/10.1287/mnsc.1040.0266

Li, S. \& Lin, B., 2006, 'Accessing information sharing and information quality in supply chain management', Decision Support Systems 42, 1641-1656. http://dx.do org $/ 10.1016 / j . d s s .2006 .02 .011$

Lin, C.Y., 2006, 'Management Information Systems: Valueing Organizational Information', Lecturer's notes on Chapter 6, viewed 04 July 2011, from http:// www.people.eku.edu/linc/cis300/notes/c06.ppt

List, B. \& Machaczek, K., 2004, 'Towards a corporate performance measurement system', Institute of Software Technology and Interactive Systems, Vienna University of Technology, Austria.

Mahidhar, V., 2005, 'Designing the lean enterprise performance measurement system', M thesis, The Systems Engineering Division, Massachusetts Institute of Technology, USA.

Merriam-Webster Online Dictionary, 2009a, Usefulness, viewed 11 January 2011 from http://www.merriam-webster.com/dictionary/usefulness

Merriam-Webster Online Dictionary, 2009b, Believability, viewed 11 January 2011, from http://www.merriam-webster.com/dictionary/believability

Merriam-Webster Online Dictionary, 2009c, Responsiveness, viewed 11 January 2011, from http://www.merriam-webster.com/dictionary/reponsiveness

Merriam-Webster Online Dictionary, 2009d, Acceptability, viewed 11 January 2011, from http://www.merriam-webster.com/dictionary/acceptability
Merriam-Webster Online Dictionary, 2009e, Comprehensiveness, viewed 11 January 2011, from http://www.merriam-webster.com/dictionary/comprehensiveness

Merriam-Webster Online Dictionary, 2010a, Relevance, viewed 30 August 2011, from http://www.merriam-webster.com/dictionary/relevance

Merriam-Webster Online Dictionary, 2010b, Accuracy, viewed 30 August 2011, from http://www.merriam-webster.com/dictionary/accuracy

Mohamed, R., Hui, W.S., Rahman, I.K.A. \& Aziz, R.A., 2008, 'Strategic performance measurement system and organization capabilities: Using levers of control framework', International Review of Business Research Papers 4(3), 151-166.

Moser, I., 2004, 'Does information flow?', Managing information flow and fluidity in medical practices, Centre for Technology, Innovation and Culture, University of Oslo, Norway.

Neely, A., 2003, Business performance: Theory and practice, Cranfield School of Management, Cambridge, Cambridge University Press.

Newcorn, D., 2003, 'Obstacles to information integration abound', Packworld.com, Packaging World Magazine 10(3), 58.

National Institute of Standards and Technology (NIST), 2002, Guidelines, information quality standards and administrative mechanism, viewed 29 April 2013, from http://www.nist.gov/director/quality_standards.htm

Organization of Economic Co-operation and Development (OECD), 2002, Glossary of statistical terms, Repeatability, viewed 01 July 2011, from http://stats.oecd.org/ glossary/detail.asp?ID=3499

Organization of Economic Co-operation and Development (OECD), 2006a, Glossary of statistical terms, Accessibility, viewed 01 July 2011, from http://stats.oecd.org/ glossary/detail.asp?ID=12

Organization of Economic Co-operation and Development (OECD), 2006b, Glossary of statistical terms, Timeliness, viewed 01 July 2011, from http://stats.oecd.org/ glossary/detail.asp?ID=3090

Ostalé, J., 2010, 'Information flow', viewed 29 April 2013, from http://glossarium. bitrum.unileon.es?Homeflujo-de-informaion/information-flow

Oz, E. \& Jones, A., 2008, Management information systems, London, Cengage Learning.

Paranjape, B., Rossiter, M. \& Pantano, V., 2006, 'Insights from the balanced scorecard performance measurement systems: Successes, failures and
future - a review', Measuring Business Excellence 10(3), 4-14. http://dx.doi. future - a review', Measuring Busin
org/10.1108/13683040610685748

Piltz, A, 2001, Computer vermittelte Kommunikation (CVK), viewed 14 March 2005 , from http://www.hausarbeiten.de/faecher/hausarbeit/inw/19351.html

Pyke, D.F. \& Cohen, M.A., 1994, 'Multi product integrated production-distribution systems', European Journal of Operational Research 74(1), 18-94. http://dx.doi. systems', European Journal of Opera
org/10.1016/0377-2217(94)90201-1

Rajamanoharan, I.D. \& Collier, P., 2006, 'Six Sigma implementation, organisational change and the impact on performance measurement systems', International Journal Six Sigma and Competitive Advantage 2(1), 48-68. http://dx.doi. Journal Six Sigma and Competitiv
org/10.1504/IJSSCA.2006.009369

Ravichandran, N., 2008, 'Managing bullwhip effect: World Trade Organisation case studies', Journal of Advances in Management Research 5(2), 77-87.

Reeker, L.H. \& Jones, A.T., 2002, 'A new classification of information: A step on the road to interpretability', viewed 30 April 2013, from http://www.isd.mel.nist. gov/research_engineering/Performance_Metrics/PerMIS_2002_Proceedings/ gov/research_engin
Reeker_Jones.pdf

Rosella Software, 2008, The balanced scorecard (BSC), viewed 06 July 2011, from http://www.roselladb.com/balanced-scorecard.htm

Saariluoma, P., 2006, 'The importance of free flow of information and knowledge', Human Technology 2(1), 13.

Salo, J. \& Karjaluoto, H., 2006, 'IT - enabled supply chain management', Contemporary Management Research 2(1), 17-30.

Santos, S., Gouveia, J.B. \& Gomes, P., 2006, 'Measuring performance in supply chain: A framework', 13th International EurOMA Conference 2006, University of Strathclyde, Glasgow, United Kingdom, June 18-21, 2006.

Scala Business Solutions NV, 2004, Supply chain management for iScala, White Paper, Amsterdam, The Netherlands.

Schuppener, B., (n.d.), Eine Neue Methode des Kommunikations Managements, Hering Schuppener, Unternehmensberatung fuer Kommunikation $\mathrm{GmbH}$, The Communications Scorecard, Frankfurt, Germany.

Serrat, O., 2010, 'The perils of performance measurement', Asian Development Bank, May, 1-7, Washington, District of Columbia.

Sezen, B., 2008, 'Relative effects of design, integration and information sharing on supply chain performance', Supply Chain Management: An International Journa 3(13), 233-240. http://dx.doi.org/10.1108/13598540810871271

Shannon, C.E., 1948, 'A mathematical theory of communication', Reprinted with corrections from The Bell Systems Technical Journal (27), 379-423, 623-656.

Simchi-Levi, D., Kaminsky, P. \& Simchi-Levi, E., 2009, (3rd edn.), Designing and managing the supply chain. Concepts, strategies, and case studies, Singapore, McGraw-Hill.

Stair, R.M. \& Reynolds, G.W., 2011, (10th edn.), Principles of information systems, Canada, Cengage Learning. 
Sullivan, M.J., McDaniel, M.F., Siegel, R.D., R\&B Consulting and McDaniel Lambert Inc., 2004, 'Environmental Protection: Using metrics to track progress of community
outreach program', Report published byAmerican Institute of Chemical Engineers, outreach program

Swink, M., Melnyk, S.A., Cooper, M.B. \& Hartley, J.L., 2011, Managing operation across the supply chain, New York, McGraw-Hill Irwin. PMCid:3240935

Trkman, P. \& Groznik, A., 2006, 'Measurement of supply chain integration benefits', Interdisciplinary Journal of Information, Knowledge, and Management (1), 38, 562.

Turban, E., Aronson, J.E., Liang, T.P. \& Sharda, R., 2007, (8th edn.), Decision support and business intelligence systems, New Jersey, Pearson.

Tyrinopoulus, Y., 2004, 'A complete conceptual model for the integrated management of the transportation work', Journal of Public Transportation 7(4), 101-120.

University of Nevada, 2010, Definition of information security, Office of Information Technology, University of Nevada, Las Vegas, viewed 03 July 2011, from http://oit. unlv.edu/network-and-security/definition-information-security
Van Eck, M., 2003, 'Advanced planning and scheduling', PhD paper for BMI, Dept. Mathematics and Computer Science, Vrije Universiteit Amsterdam.

Von Haaren, B. \& Malyshko, T., 2007, Integration of Velos-Simulation-Results into the supply chain balanced scorecard', Technical Report 07007, Universitaet Dortmund

Webster, S., 2008, Principles and tools for supply chain management, McGraw-Hill Irwin, New York.

Winkler, C., 2004, 'Getting a grip on performance', CFO.com, November 15, 2004, CFO (2011, from http://www.cfo com/article. $\mathrm{cfm} / 3373526$ ?f=search

Wu, F., Huberman, B.A., Adamic, L.A. \& Tyler, J.R., 2005, 'Information flow in socia groups', HP Laboratories, California, USA.

Ying, C., Hong, L. \& Zhengchuan, X., 2004, 'An evaluation framework for interorganisational business process modeling techniques', School of Manangement, Fudang University, Shanghai, P.R. China, viewed 06 July 2011, from http://www. pacis-net.org/file/2004/p04-12.pdf

Zerfaß, A. (2004). Die Corporate Communications Scorecard - Kennzahlensystem, Optimierungstool oder strategisches Steuerungsinstrument? prportal.de, 57, 1-8. 